\title{
Intraoperative use of dexmedetomidine for the prevention of emergence agitation and postoperative delirium in thoracic surgery: a randomized-controlled trial Utilisation peropératoire de la dexmédétomidine pour la prévention de l'agitation au réveil et du delirium postopératoire en chirurgie thoracique: essai randomisé contrôlé
}

\author{
Jie Ae Kim, MD, PhD • Hyun Joo Ahn, MD, PhD (iD - Mikyung Yang, MD, PhD • \\ Sang Hyun Lee, MD • Heejoon Jeong, MD • Bong Gyu Seong, MD
}

Received: 6 August 2018/Revised: 27 September 2018/Accepted: 10 October 2019/Published online: 24 January 2019

(c) Canadian Anesthesiologists' Society 2019

\begin{abstract}
Purpose We investigated whether preventive use of dexmedetomidine during surgery was effective for reducing emergence agitation and postoperative delirium. Methods In this double-blind randomized-controlled trial, 143 patients undergoing thoracoscopic lung resection surgery were randomly assigned to the dexmedetomidinesevoflurane (DEX-Sevo, $n=73$ ) or sevoflurane (Sevo, $n=$ 70) groups. Dexmedetomidine or saline administration was started after inducing anesthesia and continued until the end of surgery at a fixed dose $\left(0.5 \mu \mathrm{g} \cdot \mathrm{kg}^{-1} \cdot \mathrm{hr}^{-1}\right)$. The primary endpoint was the incidence of delirium up until the end of postoperative day 3. Emergence agitation and postoperative delirium were measured with the Riker sedation agitation scale and the confusion assessment method, respectively. The secondary endpoints were serum cytokine and catecholamine levels.
\end{abstract}

Results The DEX-Sevo group showed less frequent emergence agitation than the Sevo group (13\% vs $35 \%$,

This article is accompanied by an editorial. Please see Can J Anesth 2018; 65: this issue.

Electronic supplementary material The online version of this article (https://doi.org/10.1007/s12630-019-01299-7) contains supplementary material, which is available to authorized users.

J. A. Kim, MD, PhD · H. J. Ahn, MD, PhD ( $\varangle)$.

M. Yang, MD, $\mathrm{PhD} \cdot \mathrm{S}$. H. Lee, MD $\cdot \mathrm{H}$. Jeong, $\mathrm{MD}$.

B. G. Seong, MD

Department of Anesthesiology and Pain Medicine, Samsung Medical Center, Sungkyunkwan University School of Medicine, 50 Ilwon-Dong, Gangnam-Gu, Seoul 135-710, South Korea e-mail: hyunjooahn@skku.edu respectively; relative risk, 0.38; $95 \%$ confidence interval [CI], 0.18 to 0.79; $P=0.011$ ) but the incidence of delirium after discharge from the postanesthesia care unit was not different (25\% vs 25\%, DEX-Sevo vs Sevo). Both pro- and anti-inflammatory cytokines were lower in the DEX-Sevo group than in the Sevo group. Nevertheless, the interleukin (IL)6/IL10 ratio (median difference, 5.8; $95 \% \mathrm{CI}, 1.8$ to 10.0; $P=0.012$ ) and IL8/IL10 ratio (median difference, 0.8; $95 \%$ CI, 0.2 to $1.3 ; P=0.007$ ) were higher in the DEX-Sevo group than in the Sevo group, indicating a proinflammatory cytokine balance in the DEX-Sevo group. Norepinephrine and epinephrine levels were lower in the DEX-Sevo group than in the Sevo group (both, $P<0.001$ ). Conclusions Intraoperative dexmedetomidine reduced emergence agitation but not postoperative delirium in patients undergoing thoracic surgery. Dexmedetomidine seemed to affect emergence agitation through catecholamines, but not through an anti-inflammatory action.

Trial registration Clinical Research Information Service (KCT 0001877); registered 7 April, 2016.

\section{Résumé}

Objectif Nous avons cherché à savoir si l'utilisation préventive de dexmédétomidine au cours de la chirurgie pouvait réduire la survenue de l'agitation au réveil et $d u$ delirium postopératoire.

Méthodes Dans cette étude randomisée, contrôlée à double insu, 143 patients subissant une résection pulmonaire par thoracoscopie ont été randomisés dans un groupe recevant dexmédétomidine-sévoflurane (DEX-Sévo, $n=73)$ ou dans un groupe recevant 
seulement du sévoflurane (Sévo, $n=70$ ). L'administration de dexmédétomidine ou de solution saline a débuté après l'induction de l'anesthésie et a continué jusqu'à la fin de l'intervention à une dose fixe de $0,5 \mu \mathrm{g} \cdot \mathrm{kg}^{-1} \cdot \mathrm{h}^{-1}$. Le critère d'évaluation principal était l'incidence du delirium jusqu'à la fin du $3^{e}$ jour postopératoire. La survenue de l'agitation au réveil et du delirium postopératoire a été mesurée avec, respectivement, l'échelle d'agitation sous sédation de Riker et la méthode d'évaluation de la confusion. Les critères d'évaluation secondaires étaient les taux sériques de cytokines et de catécholamines.

Résultats La survenue d'une agitation au réveil a été moins fréquente dans le groupe DEX-Sévo que dans le groupe Sévo (respectivement, $13 \%$ contre $35 \%$; risque relatif, 0,38; intervalle de confiance [IC] à $95 \%: 0,18$ à 0,79; $P=0,011)$, mais l'incidence du delirium après congé de la salle de réveil n'a pas été différente entre les groupes (DEX-Sévo $25 \%$ contre Sévo $25 \%$ ). Les taux de cytokines pro- et anti-inflammatoires ont tous deux été plus bas dans le groupe DEX-Sévo que dans le groupe Sévo. Néanmoins, les ratios d'interleukines (IL) IL-6/IL-10 (différence entre médianes, 5,8; IC à 95\%, 1,8 à 10,0; $P=0,012$ ) et IL-8/IL-10 (différence des médianes, 0,8; IC à $95 \%, 0,2$ à 1,3; $P=0,007)$ ont été plus elevés dans le groupe DEX-Sévo que dans le groupe Sévo indiquant un équilibre des cytokines pro-inflammatoires dans le groupe DEX-Sévo. Les taux de norépinéphrine et d'épinéphrine ont été inférieurs dans le groupe DEX-Sévo que dans le groupe Sévo $(P<0,001$ pour les deux $)$.

Conclusions La dexmédétomidine peropératoire a réduit la survenue de l'agitation au réveil, mais pas du delirium postopératoire chez des patients subissant une chirurgie thoracique. La dexmédétomidine a semblé interférer sur la survenue de l'agitation par le biais des catécholamines, mais pas par un effet anti-inflammatoire.

Enregistrement de l'essai clinique Service d'information sur la recherche clinique (KCT 0001877); enregistré le 7 avril 2016.

Postoperative delirium is a common problem in patients undergoing major surgery, with an incidence rate of $10-60 \%$, and is associated with increased morbidity and healthcare costs. ${ }^{1}$ Nevertheless, no preventive pharmacologic strategy is available. ${ }^{2}$ Recently, a Lancet study by Su et $\mathrm{al}^{3}{ }^{3}$ showed that the $\alpha_{2}$-adrenergic receptor agonist dexmedetomidine is a potential candidate. In this study, preventive use of dexmedetomidine (infusion started on arrival in the intensive care unit [ICU] and maintained until postoperative day [POD] 1) reduced the incidence of delirium from $23 \%$ to $9 \%$ after non-cardiac surgery. Nevertheless, dexmedetomidine was administered after surgical insult in this study and questions still exist as to whether dexmedetomidine has a direct neuroprotective effect or simply reduces the dose of delirium-causing drugs or emergence agitation.

Surgery increases the production of pro-inflammatory cytokines. ${ }^{4-7}$ The inflammatory reaction is strongly related to postoperative delirium ${ }^{8,9}$ and postoperative impairment of cognitive function. ${ }^{10,11}$ Dexmedetomidine has been suggested to modulate the secretion of inflammatory cytokines through $\alpha_{2}$ adrenergic receptors on macrophages and monocytes ${ }^{12}$ and by inhibiting the synthesis of nuclear factor- $\kappa \mathrm{B}$ by activating the cholinergic anti-inflammatory pathway. ${ }^{13}$ Therefore, we speculated that preventive use of dexmedetomidine would decrease postoperative delirium by reducing the levels of pro-inflammatory cytokines in surgical patients.

Our hypothesis was that intraoperative dexmedetomidine infusion, which was started before and was maintained throughout surgery, would decrease emergence agitation during anesthesia recovery and postoperative delirium. The secondary endpoints were the differences in levels of pro- and anti-inflammatory cytokines and catecholamines between the control and dexmedetomidine infusion groups.

We conducted this study on patients undergoing thoracic surgery because these patients are at high risk of adverse outcomes when postoperative delirium occurs, and thoracic surgery and one-lung ventilation are associated with profound release of inflammatory cytokines. ${ }^{14,15}$

\section{Methods}

This prospective, randomized, double-blind study was approved by the Samsung Medical Center Institutional Review Board (IRB number: SMC 2015-10-065-006), and written informed consent was obtained from all patients participating in the trial. The trial was registered prior to patient enrolment at the Clinical Research Information Service (KCT 0001877, principal investigator: Jie Ae Kim, Date of registration: April 7, 2016).

Patients and randomization

This study was performed between April and July 2016 at a tertiary care university hospital. A total of 182 patients undergoing elective video-assisted thoracoscopic lobectomy/segmentectomy for lung cancer were assessed for eligibility, and 143 patients were enrolled. The exclusion criteria were age $>75$ or $<18 \mathrm{yr}$, American Society of Anesthesiologists physical status $>$ III, New York Heart Association class $>\Pi$, body mass index $>30$ $\mathrm{kg} \cdot \mathrm{m}^{-2}$, cardiac ejection fraction $<40 \%$, heart rate $<50 /$ 
min, arrhythmia other than first degree atrioventricular block, liver enzymes more than two-fold normal values, and serum creatinine $>1.2 \mathrm{mg} \cdot \mathrm{dL}^{-1}$. Patients with a chronic pain disorder, dementia, or drug addiction were excluded. Patients who used anti-psychotic agents, antidepressants, beta blockers, anti-arrhythmic drugs, or digoxin within one week before surgery were also excluded. Patients who used epidural patient-controlled analgesia, or who were allergic to the study drugs, were also excluded.

Randomization was done by a computer-generated random numbers table, with a fixed block size of four according to a 1:1 ratio, and the allocation was sealed in an opaque envelope. The primary investigator or coinvestigator prospectively collected the laboratory results, radiology reports, and data on the clinical course. The surgeon, patients, attending anesthesiologists, data recorder, and analyzer were blinded to the group assignments.

\section{Intraoperative management}

Anesthesia was conducted according to the same protocol in both groups. A nurse not working on the study opened a sealed envelope just before anesthesia and provided the study drug in a $50 \mathrm{~mL}$ syringe. The syringe and its content were indistinguishable between the groups. The syringe was filled with dexmedetomidine (DEX-Sevo group) $\left(0.004 \mathrm{mg} \cdot \mathrm{mL}^{-1}\right)$ or saline (Sevo group) and was infused by the attending anesthesiologist at a fixed rate of 0.125 $\mathrm{mL} \cdot \mathrm{kg}^{-1} \cdot \mathrm{hr}^{-1}$ (equivalent to $0.5 \mu \mathrm{g} \cdot \mathrm{kg}^{-1} \mathrm{hr}^{-1}$ in the DEXSevo group) after preoperative blood sampling in the operating room and immediately prior to induction of anesthesia. Anesthetic depth was titrated to maintain a bispectral index of $45 \pm 5$ and blood pressure within $20 \%$ of baseline during surgery. The maintenance fluid was lactated Ringer's solution, infused at a rate of 4 $\mathrm{mL} \cdot \mathrm{kg}^{-1} \cdot \mathrm{hr}^{-1}$. The protective ventilation protocol was the same for all patients. Dexmedetomidine or saline administration was discontinued at the end of the surgery. All patients were extubated upon meeting the extubation criteria and transferred to the ICU after anesthesia recovery in the postanesthesia care unit (PACU).

Primary endpoint: postoperative delirium

Emergence agitation was assessed in the PACU using the Riker sedation agitation scale (eAppendix 1, available as Electronic Supplementary Material [ESM]). ${ }^{16}$ The Riker sedation agitation scale was applied one minute after extubation and repeated every 15 min during the PACU stay. A score $>4$ at any of the time points was regarded as emergence agitation $(+)$. Postoperative delirium was assessed by the confusion assessment method (CAM, eAppendix 2, available as ESM $)^{17}$ after PACU discharge until POD 3; CAM-ICU was performed every four hours until ICU discharge and CAM was performed three times per day in the ward until POD 3. The assessment was done by trained nurses who were blinded to the group assignments.

Secondary variables: pro- and anti-inflammatory cytokines and catecholamines

Arterial blood samples were drawn into EDTA tubes before the study drug was infused (preoperatively) and one hour after the operation (postoperatively). The blood samples were immediately centrifuged at $1,000 \times \mathrm{g}$ for ten minutes, and the supernatant was removed and centrifuged for an additional three minutes at $7,000 \times \mathrm{g}$. The plasma was frozen at $-80^{\circ} \mathrm{C}$ until subsequent analysis. Interleukin (IL)6, IL8, and tumour necrosis factor (TNF) $\alpha$ and IL10 were analyzed using a multiplex immunoassay kit (ProcartaPlex $^{\mathrm{TM}}$; Veritas Corp., Tokyo, Japan). Specific enzyme-linked immunosorbent assays (ELISA) were used to quantify cortisol (Cortisol ELISA kit, \#500360; Cayman Chemical, Ann Arbor, MI, USA) and epinephrine/ norepinephrine (epinephrine/norepinephrine ELISA kit, \#KA1877, Abnova, Taipei, Taiwan). All analyses were performed in duplicate in accordance with the manufacturer's instructions. White blood cell (WBC) counts and C-reactive protein (CRP) levels were also monitored until hospital discharge.

\section{Anesthetic consumption and clinical outcomes}

Consumption of opioids was monitored for six postoperative hours, and all opioids except remifentanil were transformed to the dose of hydromorphone (mg) using an opioid conversion table. ${ }^{18}$ Expired sevoflurane concentration was recorded at ten-minute intervals and intraoperative consumption was recorded as the ageadjusted minimum alveolar concentration $\times$ hour. Extubation time as well as analgesic and anti-emetic use after surgery were recorded.

Complications during hospitalization were monitored based on the Clavien-Dindo classification of surgical complications (eAppendix 3, available as ESM). ${ }^{19}$ A pulmonary complication was defined as a Melbourne group-scaled pulmonary complication (eAppendix 4, available as ESM) ${ }^{20}$ Chest tube removal time and ICU and hospital stay durations were recorded. 
Fig. 1 Consort flow diagram

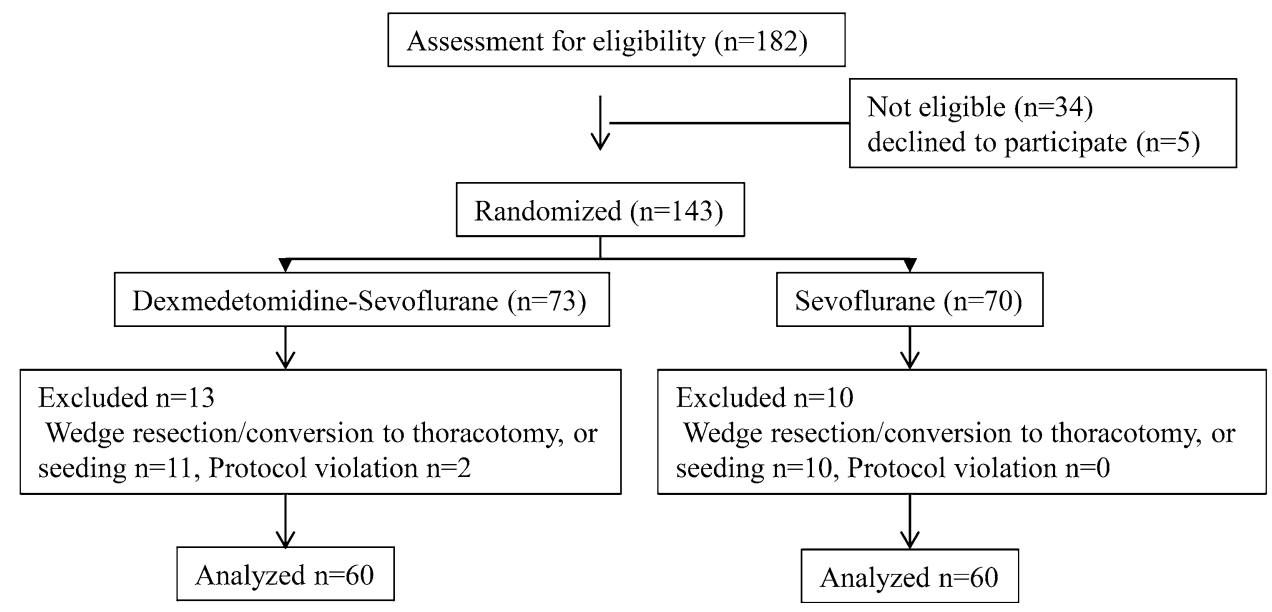

\section{Statistical analysis}

In a previous study, the incidence rates of emergence agitation were $52 \%$ and $28 \%$ in the control and dexmedetomidine infusion groups. ${ }^{21}$ Assuming a similar reduction in emergence agitation and a $10 \%$ dropout rate, 143 patients were required for a two-sided alpha of 5\% with $80 \%$ power (Pearson's Chi-square test). Dropout was predefined as a change in the operation to open surgery or a simple wedge resection, bleeding $>400 \mathrm{~mL}$, or ineligibility due to a sampling/testing error.

Continuous variables are presented as means (standard deviation [SD]) or medians [interquartile range (IQR)]. Categorical variables are described as numbers. The incidence of emergence agitation, postoperative delirium, and complications were compared using the Chi-square test. Wilcoxon rank-sum test for independent samples was used to compare postoperative cytokine and catecholamine levels between the two groups. Cytokines and catecholamines were adjusted for multiple testing using Bonferroni correction. Confidence intervals for nonnormally distributed variables were calculated using the Hodges-Lehmann estimator. All $P$-values were two-sided, and $P<0.05$ was considered significant. SAS (version 9.4; SAS Institute, Cary, NC, USA) and SigmaPlot ${ }^{\circledR}$ (version 11.2; Systat Software Inc., San Jose, CA, USA) software were used to conduct the analysis.

\section{Results}

On the day of surgery, the 143 patients were randomly divided into the Sevo group $(n=70)$ or the DEX-Sevo group $(n=73)$. Twenty-three patients dropped out because of a surgery change. Demographic characteristics and complications were compared between the two groups (120 patients excluding those with surgery changes; 60 in the
Sevo group and 60 in the DEX-Sevo group). Cytokine levels were analyzed in 116 patients, excluding four cases with a sampling error; levels were compared between the two groups, (59 in the Sevo group and 57 in the DEX-Sevo group) (Fig. 1).

The baseline characteristics of the patients and surgeries were well balanced between the DEX-Sevo and Sevo groups (Table 1).

The DEX-Sevo group showed a lower incidence of emergence agitation than the Sevo group (8 (13\%) vs 21 (35\%), respectively; relative risk, $0.38 ; 95 \%$ confidence interval $[\mathrm{CI}], 0.18$ to $0.79 ; P=0.011$ ). The distribution pattern of the Riker sedation agitation scale at one minute after extubation is shown in Fig. $2(P=0.059)$. Postoperative delirium until POD 3 was not different between the two groups (DEX-Sevo group vs Sevo group; $15(25 \%)$ vs 15 (25\%), $P=1.00)$.

Interleukin 6 was lower in the DEX-Sevo group than the Sevo group, but the difference was not statistically significant between the two groups (median difference, $-26.7 \mathrm{pg} \cdot \mathrm{mL}^{-1} ; 95 \% \mathrm{CI},-91.7$ to $\left.0.0 ; P=0.055\right)$ (Table 3 ). The other pro-inflammatory cytokine, IL8, was lower in the DEX-Sevo group than in the Sevo group (median difference, $-5.6 \mathrm{pg} \cdot \mathrm{mL}^{-1} ; 95 \% \mathrm{CI},-8.6$ to -0.4 ; $P=0.024)$. The anti-inflammatory cytokine IL10 was lower in the DEX-Sevo group than in the Sevo group (median difference, $-9.8 \mathrm{pg} \cdot \mathrm{mL}^{-1} ; 95 \% \mathrm{CI},-13.9$ to $-3.3 ; P<0.002)$. The net cytokine balance was toward the pro-inflammatory side in the DEX-Sevo group compared with the Sevo group; the IL6/IL10 ratio (median difference, 5.8; 95\% CI, 1.8 to $10.0 ; P=0.012$ ) and the IL8/IL10 ratio (median difference, $0.8 ; 95 \% \mathrm{CI}, 0.2$ to $1.3 ; P=0.007$ ) were higher in the DEX-Sevo group than the Sevo group (Table 2).

Epinephrine (median difference, $-95.2 \mathrm{pg} \cdot \mathrm{mL}^{-1} ; 95 \%$ CI, -150.8 to $-69.3 ; P<0.001)$ and norepinephrine (median difference, $-264.4 \mathrm{pg} \cdot \mathrm{mL}^{-1} ;-344.3$ to $-152.2 ; P$ 
Table 1 Patient and anesthetic profiles

\begin{tabular}{|c|c|c|}
\hline & DEX-Sevo $(n=60)$ & Sevo $(n=60)$ \\
\hline Male, $n(\%)$ & $28(47)$ & $30(50)$ \\
\hline Age (yr) & $63[58-68]$ & $59[56-65]$ \\
\hline Body mass index $\left(\mathrm{kg} \cdot \mathrm{m}^{-2}\right)$ & $24 \pm 3$ & $25 \pm 3$ \\
\hline ASA $(1 / 2), n(\%)$ & $18(30) / 42(70)$ & $20(33) / 40(67)$ \\
\hline $\mathrm{FEV}_{1}(\%)$ & $94(12)$ & $91(13)$ \\
\hline $\mathrm{FEV}_{1 /} \mathrm{FVC}(\%)$ & $75[72-78]$ & $75[69-79]$ \\
\hline $\operatorname{DLCO}(\%)$ & $93(16)$ & $93(16)$ \\
\hline Smoking (never/past/current), $n(\%)$ & $38(63) / 17(28) / 5(8)$ & $38(63) / 16(27) / 6(10)$ \\
\hline Diabetes mellitus, $n(\%)$ & $11(18)$ & $9(15)$ \\
\hline Hypertension, $n(\%)$ & $23(38)$ & $19(32)$ \\
\hline Surgery (segmentectomy/ lobectomy), $n(\%)$ & $6(10) / 54(90)$ & $7(12) / 53(88)$ \\
\hline Pathologic staging, $n(\%)$ & $34(57)$ & $33(55)$ \\
\hline T1N0 & $15(25)$ & $20(33)$ \\
\hline T2N0 & $8(13)$ & $5(9)$ \\
\hline T1N1 & $3(5)$ & $2(3)$ \\
\hline \multicolumn{3}{|l|}{$\mathrm{T} 2 \mathrm{~N} 1$} \\
\hline Adenocarcinoma/squamous/other, $n(\%)$ & $49(82) / 8(13) / 3(5)$ & $51(85) / 7(12) / 2(3)$ \\
\hline
\end{tabular}

Data were expressed as mean (standard deviation), median [interquartile range] or numbers (\%). Baseline patient characteristics between groups were well balanced (all mean standard difference were $<0.1$ )

ASA = American Society of Anesthesiologists physical status; DEX-Sevo = dexmedetomidine-sevoflurane; DLCO = diffusing capacity of the lungs for carbon monoxide; $\mathrm{FEV}_{1}=$ forced expired volume in one second; FVC = forced vital capacity; Sevo = sevoflurane

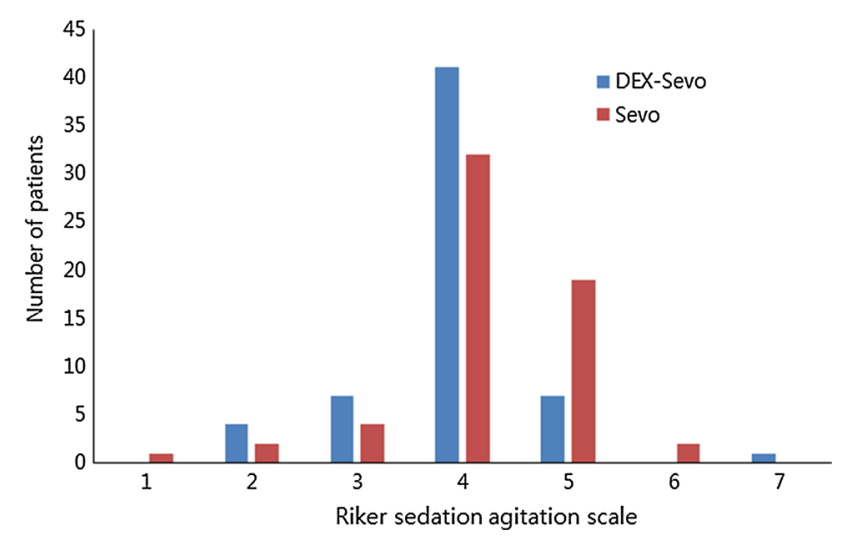

Fig. 2 Distribution of Riker sedation agitation scale at one minute after extubation. $1=$ minimal or no response to noxious stimuli; 2 arousal to physical stimuli but non-communicative; $3=$ difficult to arouse but awakens to verbal stimuli or gentle shaking; $4=$ calm and follows commands; 5 anxious or physically agitated but calms to verbal instructions; $6=$ requires restraint and frequent verbal reminding of limits; and $7=$ attempting to remove tracheal tube or catheters, or striking at staff

$<0.001)$ levels were lower in the DEX-Sevo group than in the Sevo group (Table 2).

No differences in $\mathrm{TNF} \alpha$ or cortisol were observed between the two groups. The neutrophil/lymphocyte ratio was lower in the DEX-Sevo group than in the Sevo group on POD 0. White blood cell counts and CRP levels did not differ between the two groups (Table 2).

The intraoperative requirement for inhaled anesthetics and consumption of opioids until six hours postoperatively were lower in the DEX-Sevo group than in the Sevo group (Table 3). The Clavien-Dindo classification of surgical complications, Melbourne group-scaled pulmonary complications, chest tube removal time, and ICU and hospital stay duration were not different between the two groups (Table 4).

\section{Discussion}

We did not detect any differences in the effects of control and dexmedetomidine infusion on the postoperative delirium after thoracoscopic lung resection surgery. Dexmedetomidine infusion reduced emergence agitation and catecholamine levels, but did not reduce the proinflammatory cytokine IL6, and tilted the cytokine balance toward a pro-inflammatory state.

Studies on intraoperative dexmedetomidine infusion and emergence agitation are rare in adult patients. Only two such studies have been published; one showed that dexmedetomidine decreased emergence agitation from $52 \%$ to $28 \%$ in patients who underwent nasal surgery $(n$ 
Table 2 Cytokines, catecholamines, cortisol, and inflammation markers

\begin{tabular}{|c|c|c|c|c|}
\hline & & DEX-Sevo $(n=57)$ & Sevo $(n=59)$ & Median difference $[95 \% \mathrm{CI}], P$ value \\
\hline \multirow[t]{2}{*}{$\operatorname{IL6}\left(\mathrm{pg} \cdot \mathrm{mL}^{-1}\right)$} & Pre & $1.3[1.3$ to 1.3$]$ & $1.3[1.3$ to 1.3$]$ & \\
\hline & Post & $177.7[103.2$ to 241.5$]$ & 204.5 [135.0 to 334.2$]$ & $-26.7[-91.7$ to 0$], 0.06$ \\
\hline \multirow[t]{2}{*}{$\operatorname{IL} 10\left(\mathrm{pg} \cdot \mathrm{mL}^{-1}\right)$} & Pre & $1.8[0$ to 3.5$]$ & $1.8[0$ to 3.5$]$ & \\
\hline & Post & $8.3[3.5$ to 19.8$]$ & $18.1[8.4$ to 37.4$]$ & $-9.8[-13.9$ to -3.3$], 0.002$ \\
\hline \multirow[t]{2}{*}{ IL6/IL10 } & Pre & $7.8[0.5$ to 15.6$]$ & $5.6[0.7$ to 15.6$]$ & \\
\hline & Post & $15.5[10.3$ to 32.3$]$ & $9.7[5.6$ to 18.4$]$ & $5.8[1.8$ to 10.0$], 0.01$ \\
\hline \multirow[t]{2}{*}{$\operatorname{IL} 8\left(\mathrm{pg} \cdot \mathrm{mL}^{-1}\right)$} & Pre & $6.3[2.4$ to 10.5$]$ & $8.3[5.0$ to 12.4$]$ & \\
\hline & Post & $17.0[10.5$ to 25.9$]$ & $22.6[13.9$ to 32.1$]$ & $-5.6[-8.6$ to -0.4$], 0.02$ \\
\hline \multirow[t]{2}{*}{ IL8/IL10 } & Pre & $6.1[1.0$ to 71.4$]$ & $5.7[2.4$ to 68.4$]$ & \\
\hline & Post & $2.0[0.9$ to 4.3$]$ & $1.2[0.7$ to 2.7$]$ & $0.8[0.2$ to 1.3$], 0.007$ \\
\hline \multirow[t]{2}{*}{$\mathrm{TNF} \alpha\left(\mathrm{pg} \cdot \mathrm{mL}^{-1}\right)$} & Pre & $0[0$ to 2.9$]$ & $0[0$ to 2.9$]$ & \\
\hline & Post & $1.9[0$ to 5.0$]$ & $2.9[0$ to 5.0$]$ & $-1.1[-1.1$ to 0$], 0.49$ \\
\hline \multirow[t]{2}{*}{ Epinephrine $\left(\mathrm{pg} \cdot \mathrm{mL}^{-1}\right)$} & Pre & $27.1[22.3$ to 33.2$]$ & 26.5 [22.1 to 31.3$]$ & \\
\hline & Post & $84.6[44.2$ to 128.4$]$ & $179.8[124.6$ to 450.0$]$ & $-95.2[-150.8$ to -69.3$],<0.001$ \\
\hline \multirow[t]{2}{*}{ Norepinephrine $\left(\mathrm{pg} \cdot \mathrm{mL}^{-1}\right)$} & Pre & 296.5 [189.7 to 520.5$]$ & $347.5[189.7$ to 477.5$]$ & \\
\hline & Post & $175.9[88.2$ to 240.7$]$ & $440.3[309.9$ to 598.9$]$ & $-264.4[-344.3$ to -152.2$],<0.001$ \\
\hline \multirow[t]{2}{*}{ Cortisol $\left(\mu \mathrm{g} \cdot \mathrm{mL}^{-1}\right)$} & Pre & $1.4[0.8$ to 2.4$]$ & $1.1[0.5$ to 2.2$]$ & \\
\hline & Post & $9.4[7.0$ to 18.6$]$ & $11.4[7.6$ to 22.2$]$ & $-2.0[-4.4$ to 1.1$], 0.2$ \\
\hline POD 0 WBC $\left(10^{3}\right.$ cells $\left.\cdot \mathrm{mL}^{-1}\right)$ & & 14.7 [12.3 to 16.3$]$ & $15.2[12.4$ to 17.4$]$ & $-0.4[-2.0$ to 0.8$], 0.5$ \\
\hline POD 0 NLR & & $2.3[1.5$ to 4.7$]$ & $9.4[6.5$ to 12.8$]$ & $-9.0[-9.9$ to -7.9$],<0.001$ \\
\hline POD 1 CRP $\left(\mathrm{mg} \cdot \mathrm{L}^{-1}\right)$ & & $2.0[1.5$ to 3.1$]$ & $2.0[1.5$ to 3.2$]$ & $0[-0.4$ to 0.4$], 0.9$ \\
\hline
\end{tabular}

Data were expressed as median [interquartile range]. Preoperative cytokine, catecholamine, and cortisol measurements were well balanced between groups (all standardized differences $<0.1)$. Each postoperative value was different from the corresponding preoperative value $(P<$ 0.05). Cytokines and catecholamines were adjusted for multiple testing using Bonferroni correction, and the corrected $P$ values are presented here

$\mathrm{CI}=$ confidence interval; $\mathrm{CRP}=\mathrm{C}$-reactive protein; DEX-Sevo = dexmedetomidine-sevoflurane; $\mathrm{IL}=$ interleukin; NLR $=$ neutrophil to lymphocyte ratio of $\mathrm{WBC} ; \mathrm{POD}=$ postoperative day; Post $=$ postoperative; Pre = preoperative; Sevo = sevoflurane; $\mathrm{TNF} \alpha=$ tumour necrosis factor $\alpha$ WBC $=$ white blood cell count

$=50$ /group). ${ }^{21}$ The other study compared a dexmedetomidine infusion group with two other groups (epidural and control, $n=30$ each group) during a gastrectomy and showed that dexmedetomidine decreased emergence agitation compared with the control $(7 \%$ vs $27 \%) .{ }^{22}$ Our result is in line with these previous studies. According to our distribution graph of Riker scales, most patients were scale 4 (calm, 41/60, 68.3\%) in the DEXSevo group. Therefore, the reduced emergence agitation shown in the DEX-Sevo group was not due to more profound sedation than the Sevo group.

In the current study, preventive use of dexmedetomidine did not reduce the incidence of postoperative delirium. Two major studies, published in the Lancet $^{3}$ and JAMA Surgery, ${ }^{23}$ showed contradictory results following noncardiac surgery; one infused dexmedetomidine just after ICU admission and maintained it until POD1 and showed a reduction in the delirium rate $(23 \%$ vs $9 \%$, saline vs dexmedetomidine group). ${ }^{3}$ The other infused dexmedetomidine during surgery and for two hours in the PACU and did not find a difference in the delirium rate $\left(12.2 \%\right.$ vs $11.4 \%$, dexmedetomidine vs saline). ${ }^{23} \mathrm{We}$ administered dexmedetomidine before surgical injury to prevent the pro-inflammatory cascade and measured cytokine levels. Our finding agrees with the negative result. We also provide evidence that reduction of emergence agitation is not associated with reduced postoperative delirium. ${ }^{24}$

None of the previous studies measured cytokines or catecholamines in relation to emergence agitation and postoperative delirium. Our study showed that dexmedetomidine infusion tended to reduce all pro-and anti-inflammatory cytokines (IL6; but without significance). Nevertheless, a greater reduction in IL10 and subsequently higher IL6/IL10 and IL8/IL10 ratios revealed a lack of any anti-inflammatory activity, or even a pro-inflammatory tendency, in the DEX-Sevo group. Interleukin 6 is the chief stimulator of most acute-phase proteins. ${ }^{25,26}$ Interleukin 10 is a cytokine with potent antiinflammatory properties that plays a central role in limiting host inflammatory and immune responses. ${ }^{27}$ The IL6/IL10 
Table 3 Anesthetic and postoperative profiles

\begin{tabular}{|c|c|c|c|}
\hline & DEX-Sevo $(n=60)$ & Sevo $(n=60)$ & Median difference or relative risk $[95 \% \mathrm{CI}], P$ value \\
\hline Operation duration (min) & $118[97-136]$ & $113[95-146]$ & $5[-8$ to 17$], 0.46$ \\
\hline One-lung ventilation duration ( $\mathrm{min}$ ) & $98[80-130]$ & 100 [77-117] & $-4[-16$ to 5$], 0.41$ \\
\hline Fluid balance $(\mathrm{mL})$ & 515 [315-699] & $515[350-605]$ & $2[-97$ to 100$], 0.92$ \\
\hline Vasoactive drugs during surgery, $n(\%)$ & $51(85)$ & $42(70)$ & 1.2 [1.0 to 1.5$], 0.08$ \\
\hline Blood loss (mL) & $100[50-100]$ & $100[50-100]$ & $-9[-22$ to 13$], 0.42$ \\
\hline Sevoflurane (MAC $\times$ hour) & $1.9[1.6-2.3]$ & $2.3[2.0-2.8]$ & $-0.4[-0.6$ to -0.2$],<0.001$ \\
\hline Intraoperative remifentanil (mg) & $0.30[0.20-0.40]$ & $0.40[0.25-0.50]$ & $-0.1[-0.05$ to -0.10$],<0.001$ \\
\hline PACU opioids (mg) & $0.3[0.0-0.5]$ & $0.5[0.0-0.7]$ & $-0.3[-0.2$ to 0$], 0.021$ \\
\hline PACU NRS & $3[3-5]$ & $5[3-7]$ & $-2[-2$ to 0$], 0.004$ \\
\hline PACU anti-emetics, n (\%) & $1(1.7)$ & $6(10.0)$ & 0.17 [0.02 to 1.34$], 0.12$ \\
\hline Opioids, postoperative 1-6 hr (mg) & $0[0-1]$ & $1[0-1]$ & $-1.0[-1.0$ to 0$], 0.003$ \\
\hline Anti-emetics, postoperative $1-6 \mathrm{hr}, n(\%)$ & $11(18.3)$ & $16(26.7)$ & $0.69[0.35$ to 1.36$], 0.38$ \\
\hline Time to obey & $7[4-12]$ & $9[6-12]$ & $-2[-3$ to 0$], 0.10$ \\
\hline Extubation time (min) & $9[6-13]$ & 9 [7-13] & $0[-2$ to 1$], 0.52$ \\
\hline $\mathrm{PaCO}_{2}(\mathrm{mmHg})$ & $38[35-42]$ & 37 [33-39] & $1.5[-0.2$ to 3.8$], 0.21$ \\
\hline $\mathrm{PaO}_{2}(\mathrm{mmHg})$ & $76[69-86]$ & $75[69-84]$ & $0.8[-3.3$ to 7.1$], 0.29$ \\
\hline PACU stay (min) & $70[60-85]$ & $68.5[60-80]$ & $1.5[-3$ to 9$], 0.23$ \\
\hline
\end{tabular}

Data were expressed as median [interquartile range] or numbers (\%). Opioids were transformed to the dose of hydromorphone (mg) based on an opioid conversion table. $\mathrm{PaCO}_{2}$ and $\mathrm{PaO}_{2}$ were measured one hour after arrival at the PACU

$\mathrm{CI}=$ confidence interval; DEX-Sevo $=$ dexmedetomidine-sevoflurane; Fluid balance $=$ input (fluid) - output (blood loss + urine + chest tube); $\mathrm{MAC}=$ minimum alveolar concentration; NRS $=$ numeric rating scale for pain; PACU $=$ postanesthesia care unit; Sevo = sevoflurane

Table 4 Clinical outcomes

\begin{tabular}{|c|c|c|c|c|}
\hline & \multicolumn{4}{|l|}{ Group } \\
\hline & $\begin{array}{l}\text { DEX-Sevo } \\
(n=60)\end{array}$ & $\begin{array}{l}\text { Sevo } \\
(n=60)\end{array}$ & Relative risk $[95 \% \mathrm{CI}]$ & $P$ \\
\hline Surgical complication & $7(12)$ & $11(18)$ & $0.6[0.27$ to 1.53$]$ & 0.44 \\
\hline Pulmonary complication & $6(10)$ & $6(10)$ & $1.0[0.34$ to 2.93$]$ & 0.76 \\
\hline Delayed chest tube removal & $2(3)$ & $7(12)$ & $0.29[0.06$ to 1.32$]$ & 0.17 \\
\hline Delayed ICU stay & $3(5)$ & $8(13)$ & $0.38[0.10$ to 1.35$]$ & 0.21 \\
\hline Delayed hospital discharge & $7(12)$ & $5(8)$ & $1.4[0.47$ to 4.1$]$ & 0.76 \\
\hline
\end{tabular}

Data were expressed as numbers (\%). There were no difference between the two groups. Surgical complications occurred when the ClavienDindo classification of surgical complication Grade was $>1$. Pulmonary complication was defined as Melbourne group-scaled pulmonary complication $\geq 4$. Delayed chest tube removal, ICU stay and hospital stay mean $>$ five days, $24 \mathrm{hr}$, and $>$ seven days, respectively

$\mathrm{CI}=$ confidence interval; DEX-Sevo = dexmedetomidine-sevoflurane; ICU = intensive care unit; IL = interleukin; Sevo = sevoflurane

ratio indicates the inflammatory balance and predicts the severity of the systemic inflammatory response. ${ }^{28,29}$

Previous studies have reported inconsistent results on the changes in cytokines caused by dexmedetomidine. ${ }^{4,6,18,30-32}$ Few have reported IL6/IL10 or IL8/IL10 ratios. Most studies used small sample sizes and employed ELISA to measure cytokines. We enrolled the largest number of patients among all such studies and used a more precise technique to measure cytokines: the ProcartaPlex ${ }^{\mathrm{TM}}$ kit and BioPlex200. ${ }^{33}$ Based on our results, intraoperative dexmedetomidine does not exert an anti- inflammatory effect because it suppresses IL10 more so than the other cytokines. Our other laboratory results also supported the lack of an anti-inflammatory effect of intraoperative dexmedetomidine; TNF $\alpha$, cortisol, WBC, and CRP levels did not differ between the two groups.

In the current study, intraoperative infusion of dexmedetomidine decreased both norepinephrine and epinephrine. $\alpha 2$-adrenergic receptor agonists, which decrease the release of catecholamines, have analgesic, anxiolytic, and hypnotic effects. ${ }^{34}$ Pain, use of inhalation agents, and opioids are among the risk factors for 
delirium. ${ }^{8,30,35}$ Dexmedetomidine reduced pain and consumption of inhalation agents and opioids in our study. Furthermore, dexmedetomidine exerts hypnotic properties by activating the endogenous sleep-promoting pathway to produce a stage II non-rapid eye movement sleep-like state through the $\alpha_{2}$-adrenergic receptor. ${ }^{36,37}$ Differences in the quality of sedation/hypnosis may be related to reduced agitation during emergence from anesthesia or deep sedation in the ICU. ${ }^{3}$ Our cytokine and catecholamine results may explain why dexmedetomidine had no anti-delirium effect but only an anti-emergence agitation effect.

The lack of an anti-inflammatory action may be explained by catecholamine-cytokine crosstalk. When pro-inflammatory cytokine levels increase in the blood, stress hormones, such as catecholamines and cortisol, are secreted by the brain. These hormones act on $\beta_{2^{-}}$ adrenoreceptors and corticoid receptors in monocytes and activate the secretion of IL10. ${ }^{38,39}$ Low levels of serum catecholamines in response to dexmedetomidine may have blocked the compensatory release of IL10, thereby altering the pro-and anti-inflammatory cytokine balance.

This study has several limitations. First, the cytokine measurements were only made twice, before and after surgery; thus, it was not possible to assess how long the effect lasted. Nevertheless, we referenced a previous study on major vascular surgery, where IL6 and IL8 levels peaked $30 \mathrm{~min}$ after the operation and started to decrease until POD $1 .{ }^{40}$ In addition, we wanted to study the impact of intraoperative dexmedetomidine infusion on proinflammatory cytokines during the intraoperative period. Thus, cytokine levels shortly after the operation was the most important values. Second, neuro-inflammation may continue in the postoperative period and stopping dexmedetomidine administration early may be related to the lack of effect on delirium. Third, the effective dose of dexmedetomidine for anti-inflammatory action is unknown. The dose used in this study $\left(0.5 \mu \mathrm{g} \cdot \mathrm{kg}^{-1} \cdot \mathrm{hr}^{-1}\right)$ was similar to that used in previous studies $(0.3-0.5$ $\left.\mu \mathrm{g} \cdot \mathrm{kg}^{-1} \cdot \mathrm{hr}^{-1}\right){ }^{4-6,19,26-28}$ Fourth, underlying pulmonary disease and one-lung ventilation could be confounding factors when applying our results to other surgeries.

In conclusion, intraoperative use of dexmedetomidine decreased emergence agitation, but did not prevent postoperative delirium in patients who underwent thoracic surgery. Reduction of emergence agitation was not related to the reduction of postoperative delirium. Patients who received dexmedetomidine had reduced catecholamine levels, but did not show reduced inflammation.

Acknowledgements The authors thank Kyunga Kim, PhD (Statistics and Data Center, Research Institute for Future Medicine,
Samsung Medical Center, Seoul, South Korea) for statistical analysis, and Miyeon Kang and Mijung Oh (the Basic Research Support Center at Samsung Biomedical Research Institute) for immunologic analysis.

Conflicts of interest None declared.

Editorial responsibility :This submission was handled by Dr. Philip M. Jones, Associate Editor, Canadian Journal of Anesthesia.

Author contributions All authors were involved in the study design, planning, study conduct, data analysis, revising, and drafting the manuscript.

Funding This study was supported by Samsung Medical Center grant [\# OTA1503201].

\section{References}

1. American Geriatrics Society Expert Panel on Postoperative Delirium in Older Adults. Postoperative delirium in older adults: best practice statement from the American Geriatrics Society. J Am Coll Surg 2015; 220: 136-48.e1.

2. Avramescu $S$, Wang DS, Choi S, Orser BA. Preventing delirium: beyond dexmedetomidine. Lancet 2017; 389: 1009.

3. Su X, Meng ZT, Wu XH, et al. Dexmedetomidine for prevention of delirium in elderly patients after non-cardiac surgery: a randomised, double-blind, placebo-controlled trial. Lancet 2016; 388: 1893-902.

4. Kang SH, Kim YS, Hong TH, et al. Effects of dexmedetomidine on inflammatory responses in patients undergoing laparoscopic cholecystectomy. Acta Anaesthesiol Scand 2013; 57: 480-7.

5. Ueki M, Kawasaki T, Habe K, Hamada K, Kawasaki C, Sata T. The effects of dexmedetomidine on inflammatory mediators after cardiopulmonary bypass. Anaesthesia 2014; 69: 693-700.

6. $\mathrm{Li}$ B, Li Y, Tian $S$, et al. Anti-inflammatory effects of perioperative dexmedetomidine administered as an adjunct to general anesthesia: a meta-analysis. Sci Rep 2015; 5: 12342.

7. Zhang J, Zhang $W$. Effects of dexmedetomidine on inflammatory responses in patients undergoing cardiac valve replacement with cardiopulmonary bypass. Chin J Anesthesiol 2013; 33: 1188-91.

8. Fong TG, Tulebaev SR, Inouyev SK. Delirium in elderly adults: diagnosis, prevention and treatment. Nat Rev Neurol 2009; 5: 210-20.

9. Capri M, Yani SL, Chattat $R$, et al. Pre-operative, high-IL-6 blood level is a risk factor of post-operative delirium onset in old patients. Front Endocrinol (Lausanne) 2014; 5: 173.

10. Wan $Y, X u J$, Ma D, Zeng $Y$, Gibelli M, Maze M. Postoperative impairment of cognitive function in rats: a possible role for cytokine-mediated inflammation in the hippocampus. Anesthesiology 2007; 106: 436-43.

11. Chen SY, Koo BN. Postoperative cognitive dysfunction: advances based on pre-clinical studies. Anesth Pain Med 2018; 13: 113-21.

12. Kawasaki T, Kawasaki C, Ueki M, Hamada K, Habe K, Sata T. Dexmedetomidine suppresses proinflammatory mediator production in human whole blood in vitro. $\mathrm{J}$ Trauma Acute Care Surg 2013; 74: 1370-5.

13. Liu Z, Wang $Y$, Wang $Y$, et al. Dexmedetomidine attenuates inflammatory reaction in the lung tissues of septic mice by activating cholinergic anti-inflammatory pathway. Int Immunopharmacol 2016; 35: 210-6. 
14. de la Gala F, Piñeiro P, Garutti I, et al. Systemic and alveolar inflammatory response in the dependent and nondependent lung in patients undergoing lung resection surgery: a prospective observational study. Eur J Anaesthesiol 2015; 32: 872-80.

15. Sugasawa Y, Yamaguchi K, Kumakura S, et al. The effect of onelung ventilation upon pulmonary inflammatory responses during lung resection. J Anesth 2011; 25: 170-7.

16. Riker RR, Picard JT, Fraser GL. Prospective evaluation of the Sedation-Agitation Scale for adult critically ill patients. Crit Care Med 1999; 27: 1325-9.

17. Ely EW, Margolin R, Francis J, et al. Evaluation of delirium in critically ill patients: validation of the Confusion Assessment Method for the Intensive Care Unit (CAM-ICU). Crit Care Med 2001; 29: 1370-9.

18. Shaheen PE, Walsh D, Lasheen W, Davis MP, Lagman RL. Opioid equianalgesic tables: are they all equally dangerous? J Pain Symptom Manage 2009; 38: 409-17.

19. Dindo D, Demartines $N$, Clavien PA. Classification of surgical complications: a new proposal with evaluation in a cohort of 6336 patients and results of a survey. Ann Surg 2004; 240: 20513.

20. Agostini P, Naidu B, Cieslik H, et al. Comparison of recognition tools for postoperative pulmonary complications following thoracotomy. Physiotherapy 2011; 97: 278-83.

21. Kim SY, Kim JM, Lee JH, Song BM, Koo BN. Efficacy of intraoperative dexmedetomidine infusion on emergence agitation and quality of recovery after nasal surgery. Br J Anaesth 2013; 111: 222-8.

22. Li Y, Wang B, Zhang LL, et al. Dexmedetomidine combined with general anesthesia provides similar intraoperative stress response reduction when compared with a combined general and epidural anesthetic technique. Anesth Analg 2016; 122: 1202-10.

23. Deiner $S$, Luo $S$, Lin HM, et al. Intraoperative infusion of dexmedetomidine for prevention of postoperative delirium and cognitive dysfunction in elderly patients undergoing major elective noncardiac surgery a randomized clinical trial. JAMA Surg 2017; 152: e171505.

24. Card E, Pandharipande P, Tomes $C$, et al. Emergence from general anaesthesia and evolution of delirium signs in the postanaesthesia care unit. Br J Anaesth 2015; 115: 411-7.

25. Gauldie J, Richards C, Harnish D, Lansdorp P, Baumann $H$. Interferon beta $2 / \mathrm{B}$-cell stimulatory factor type 2 shares identity with monocyte-derived hepatocyte-stimulating factor and regulates the major acute phase protein response in liver cells. Proc Natl Acad Sci USA 1987; 84: 7251-5.

26. Sakamoto K, Arakawa H, Mita S, et al. Elevation of circulating interleukin 6 after surgery: factors influencing the serum level. Cytokine 1994; 6: 181-6.

27. Lyer SS, Cheng $G$. Role of interleukin 10 transcriptional regulation in inflammation and autoimmune disease. Crit Rev Immunol 2012; 32: 23-63.
28. Taniguchi T, Koido Y, Aiboshi J, Yamashita T, Suzaki S, Kurokawa $A$. The ratio of interleukin-6 to interleukin-10 correlates with severity in patients with chest and abdominal trauma. Am J Emerg Med 1999; 17: 548-51.

29. Weis F, Beiras-Fernandez A, Schelling G, et al. Stress doses of hydrocortisone in high-risk patients undergoing cardiac surgery: effects on interleukin-6 to interleukin-10 ratio and early outcome. Crit Care Med 2009; 37: 1685-90.

30. Bekker A, Haile $M$, Kline $R$, et al. The effect of intraoperative infusion of dexmedetomidine on the quality of recovery after major spinal surgery. J Neurosurg Anesthesiol 2013; 25: 16-24.

31. Chen S, Hua F, Lu J, et al. Effect of dexmedetomidine on myocardial ischemia-reperfusion injury. Int $\mathrm{J}$ Clin Exp Med 2015; 8: 21166-72.

32. Wang $Z X$, Huang $C Y$, Hua YP, Huang WQ, Deng LH, Liu KX. Dexmedetomidine reduces intestinal and hepatic injury after hepatectomy with inflow occlusion under general anaesthesia: a randomized controlled trial. Br J Anaesth 2014; 112: 1055-64.

33. Elshal MF, McCoy JP. Multiplex bead array assays: performance evaluation and comparison of sensitivity to ELISA. Methods 2006; 38: 317-23.

34. Gertler R, Brown HC, Mitchell DH, Silvius EN. Dexmedetomidine: a novel sedative-analgesic agent. Proc (Bayl Univ Med Cent) 2001; 14: 13-21.

35. Yu D, Chai W, Sun X, Yao L. Emergence agitation in adults: risk factors in 2,000 patients. Can J Anesth 2010; 57: 843-8.

36. Nelson LE, Lu J, Guo T, Saper CB, Franks NP, Maze M. The alpha2-adrenoceptor agonist dexmedetomidine converges on an endogenous sleep-promoting pathway to exert its sedative effects. Anesthesiology 2003; 98: 428-36.

37. Huupponen E, Maksimow A, Lapinlampi $P$, et al. Electroencephalogram spindle activity during dexmedetomidine sedation and physiological sleep. Acta Anaesthesiol Scand 2008; 52: 289-94.

38. Woiciechowsky C, Schöning B, Lanksch WR, Volk HD, Döcke $W D$. Mechanisms of brain-mediated systemic anti-inflammatory syndrome causing immunodepression. J Mol Med (Berl) 1999; 77: 769-80.

39. Woiciechowsky C, Asadullah K, Nestler D, et al. Sympathetic activation triggers systemic interleukin-10 release in immunodepression induced by brain injury. Nat Med 1998; 4: 808-13.

40. Lindholm EE, Aune E, Seljeflot I, Otterstad JE, Kirkebøen KA. Biomarkers of inflammation in major vascular surgery: a prospective randomised trial. Acta Anaesthesiol Scand 2015; 59: 773-87.

Publisher's Note Springer Nature remains neutral with regard to jurisdictional claims in published maps and institutional affiliations. 